\title{
Simone Messina e Valeria Ramacciotti (a cura di), L'autorità e le prove della storia
}

\section{Paola Sosso}

\section{(2) OpenEdition}

\section{Journals}

\section{Edizione digitale}

URL: http://journals.openedition.org/studifrancesi/8257

DOI: 10.4000/studifrancesi.8257

ISSN: 2421-5856

\section{Editore}

Rosenberg \& Sellier

\section{Edizione cartacea}

Data di pubblicazione: 1 mai 2009

Paginazione: 172

ISSN: 0039-2944

\section{Notizia bibliografica digitale}

Paola Sosso, «Simone Messina e Valeria Ramacciotti (a cura di), L'autorità e le prove della storia», Studi Francesi [Online], 157 (LIII | I) | 2009, online dal 30 novembre 2015, consultato il 13 janvier 2021. URL: http://journals.openedition.org/studifrancesi/8257 ; DOI: https://doi.org/10.4000/studifrancesi.8257

Questo documento è stato generato automaticamente il 13 janvier 2021.

\section{cc) $(1) \odot$}

Studi Francesi è distribuita con Licenza Creative Commons Attribuzione - Non commerciale - Non opere derivate 4.0 Internazionale. 


\title{
Simone Messina e Valeria Ramacciotti (a cura di), L'autorità e le prove della storia
}

\author{
Paola Sosso
}

\section{NOTIZIA}

SIMONE MESSINA E VALERIA RAMACCIOTTI (a cura di), L'autorità e le prove della storia, Alessandria, Edizione dell'Orso («Metamorfosi dei Lumi, 4»), 2007, pp. 178.

1 Nella Premessa al volume Simone Messina spiega come questa seconda raccolta di saggi del Centro Studi interdisciplinare «Metamorfosi dei Lumi» dell'Università di Torino intenda ampliare la ricerca a vari settori della cultura, della politica e della letteratura per mettere in evidenza la contestazione della società tradizionale e l'imporsi di nuove forme di autorità che si verificò tra fine Settecento e inizio Ottocento. Una prima sezione, dedicata a «Il modello libertino», si apre con lo studio di Stéphanie GENAND (Rédéfinition de l'autorité au tournant des Lumières, pp. 3-16), in cui l'autrice spiega come l'evoluzione tardiva del romanzo libertino permetta di analizzare la messa in causa dell'autorità. Molti autori minori si buttano infatti sul genere, garanzia di successo commerciale: vi è così un fenomeno di democratizzazione della scrittura che va di pari passo con l'imitazione dei grandi modelli e con l'utilizzo di forme di scrittura eterogenee in cui si mischiano generi e registri. Valentina PONZETTO (Le libertin et le citoyen. Modèles et contre-modèles d'autorité dans le cycle de "Faublas", pp. 17-34) parte dai due modelli comportamentali offerti dal testo di Louvet: il libertino e il cittadino. Se fin dall'inizio del testo sembra di essere nella linea del romanzo mondano e libertino, l'autore propone in realtà esempi di virtù individuali e di senso del dovere, in particolare nella figura del barone de Faublas e in quella di M. du Portail/Lovzinski. Il finale arriva poi a reintegrare il protagonista nella comunità morale, anche se la fortuna del romanzo nel xIX secolo rimane legata per lo più alla figura del protagonista 
seduttore. Michel Delon (“Faublas" et la question de l'autorité ou la promotion du médecin, pp. 35-47) parte dagli elementi caratterizzanti il modello libertino per illustrare in seguito gli aspetti innovativi di Les Amours de Faublas rispetto alla tradizione che lo ha preceduto: alla frivolezza parigina si affianca il patriottismo polacco, al modello del seduttore fa da contrasto, nelle figure di Lovinski e di Pulauskiude, un'autorità morale e politica. Ma è soprattutto la figura del medico ad assumere un valore particolare nel romanzo: la sua funzione diviene infatti quella di una guida morale in grado di supplire alle istituzioni in declino.

2 Nella seconda sezione, "Idoli infranti», troviamo un articolo di Anna BATTAGLIA che, dopo essersi occupata del rapporto tra autorità politica e lingua in Francia attraverso $i$ secoli, si sofferma sul dizionario dell'abbé Féraud (La lingua in Francia tra autoritarismo $e$ spinta innovatrice: il "Diction(n)aire critique" dell'abbé Féraud (1787-1788, pp. 51-72) per mostrare come si tratti di un esempio di dissonanza all'interno della tradizione, ad esempio nei rimandi all'Académie française dove si trova con una certa frequenza una sottile polemica, o nel tentativo di conferire legittimità ad alcune pratiche linguistiche legate all'oralità. Wilma PROGLIO in Paolina Grismondi e l'autorità culturale della Francia (pp. 73-87) ricostruisce le vicende della poetessa arcade nota con lo pseudonimo Lesbia Cidonia evidenziando il suo amore per i costumi e le novità francesi. L'autorità esercitata dalla Francia nella formazione della contessa bergamasca si ritrova in vari ambiti, dalla lingua alla letteratura, dal teatro ai costumi. La statue brisée. "Mémoires secrets" et "Vies privées" de Napoléon Bonaparte è il titolo del contributo di Simone MESSINA (pp. 89-110), la quale si interessa ai numerosi testi che, a partire dal 1814, si occupano della biografia di Napoleone tentando di rivelare aspetti inediti della sua vita privata. La maggior parte di queste memorie è opera di Charles Doris, di cui è stato fino ad oggi impossibile ricostruire l'identità esatta. Si tratta di testi preceduti da prefazioni in cui l'autore rivendica il carattere serio e l'imparzialità del suo lavoro, nato dalla conoscenza diretta del personaggio descritto. La figura di Napoleone è presentata con un chiaro interesse per gli elementi concreti della vita dell'uomo e col fine di giungere ad alcune considerazioni morali sull'esercizio del potere. Appare evidente il profondo fascino di un uomo considerato eccezionale, terribile, diverso, pur nel realismo delle descrizioni della vita quotidiana. Marina SPADARO (Santi, apostoli, giacobini. Immagini dell'autorità religiosa ed istruzione del popolo sovrano nel decennio 1789-1799, pp.111-130) sofferma la sua attenzione sull'ambito italiano e su alcuni di quei "Catechismi repubblicani" che offrono un'immagine di Gesù Cristo come democratico patriota, divino legislatore e degli Apostoli come patrioti democratici: attraverso il Vangelo e l'immagine di Cristo si definiva in tal modo la battaglia contro i privilegi che si apriva ad una rigenerazione politica e ad una riforma. Ritorniamo in ambito francese con l'intervento di Ivanna Rosi (Polemica politica e ritratti di sovrani nei "Mémoires d'OutreTombe", pp. 131-147) la quale ci presenta uno Chateaubriand ritrattista, che si riserva di mettere in luce le caratteristiche umane individuali. Napoleone è ammirato per la sua forza dominatrice, ma disprezzato per il tirannico cinismo, Luigi XVIII è definito egoista e privo di pregiudizi, con evidenti difetti che influiscono sull'esercizio delle sue funzioni, mentre il fallimento storico dei Borboni è analizzato con un «rire moqueur et éternel». Una nuova autorità sembra imporsi, quella della parola, capace di giudicare senza remore colpe e debolezze del potere politico.

3 Chiude il volume la sezione "Autorità dello scrittore» che comprende due studi: quello di Chiara SANDRIN (Il tema del racconto "Der Findling" di Heinrich Kleist, pp. 151-158) e 
quello di Massimo BACIGALUPO (William Wordsworth, la riflessione metapoetica dell'autorità, pp. 159-178) che non riguardando l'ambito francese ci limitiamo a segnalare. 